\title{
Protective factors contributing to teacher-working environment fit in Italian teachers' sample
}

\section{DOI: http://doi.org/10.26758/9.1.1}

Simona DE STASIO (1), Francesca BOLDRINI (1), Benedetta RAGNI (1), Chiara BACILE (1)

(1) Department of Human Studies, Lumsa, Roma, Italy

Address correspondence to: Simona De Stasio, Department of Human Studies, Lumsa, Piazza delle Vaschette, 101 - 00193 Roma, Italy; Ph.: ++39-06-68-42-29-11;

E-mail: s.destasio@,lumsa.it

\begin{abstract}
Objectives. Main purposes of our study were to examine in a sample of teachers involved in educational and scholastic services for children between 0 and 6 years old: a) the relationship between work environment fit and some dispositional and socio-contextual variables teachers age; b) the predictive role of subjective happiness, work engagement, collective efficacy and some socio-contextual variables (self/co-regulated proactive strategies) on teachers' workingenvironment fit.

Material and methods. Our sample was composed of 189 full-time in-service teachers $(89 \%$ female) from Rome, Italy. Age ranged from 27 to 63 years old $(\mathrm{M}=36.03$ years, $\mathrm{SD}=10.15)$. All teachers subjected to: Subjective Happiness Scale (Lyubomirsky and Lepper, 1999), Utrecht Work Engagement Scale (UWES-17; Schaufeli and Bakker, 2004, Italian version of UWES-17, validated by Balducci, Fraccaroli and Schaufeli, 2010), Proactive Strategy Scale (Pyhältö, Pietarinen and Salmela-Aro, 2011, Salmela-Aro, 2009) and Teacher-working environment fit scale (Pyhältö, Pietarinen and Salmela-Aro, 2011).

Results. The main findings of regression model analysis conducted show that teachers' proactive co-regulation strategies $(\beta=.379, \mathrm{t}=5.713, \mathrm{p}<.001)$, perceived collective self-efficacy $(\beta=$ $.252, \mathrm{t}=5.015, \mathrm{p}<.001)$, work engagement levels $(\beta=.166, \mathrm{t}=2.857, \mathrm{p}=.005)$, and subjective happiness $(\beta=.115, \mathrm{t}=-2.105, \mathrm{p}=.036)$ all positive predicted working environment fit.

Conclusions. The identification of factors sustaining teachers in their work environment represents a considerable resource, preventing the risk of distress and avoiding its extreme consequences, such as burnout and turnover.
\end{abstract}

Keywords: work environment fit, early childhood teachers, subjective well-being, work engagement.

\section{Introduction}

Early childhood teachers' work occurs in a social context and it is especially social for that teachers working in teams that call for ongoing contact among colleagues, principles, and members of other workgroups (Leiter et al., 2012). Different studies highlighted that the highly relational nature of the early childhood work environment has a relevant effect on teachers' wellbeing. A positive climate (Hoy and Spero, 2005), receiving constructive feedback and professional recognition at school from colleagues and principles (Stoeber and Rennert, 2008), may play a central role in promoting job satisfaction, and work engagement which, in turn, improve job performance (Xanthopoulou et al., 2009). In a recent large-scale study carried out by Johnson, Kraft and Papay (2012) teachers identified three key characteristics of schools as 
working environments: working relationships with colleagues, school principal's leadership, and characteristics of the school culture that contribute to teachers' work satisfaction and retention. As some authors noted, it is worthwhile to understand the factors contributing to teachers' working environment as well as the preventive measure that can be endorsed to contrast stress, taken into account that teachers can also modify their working environments by using different strategies to cope with the stressors (Bermejo-Toro, Prieto-Ursúa and Hernández, 2016).

The few existing studies, examining teachers' working environment, have shown that personal and social factors impact on organizational outcomes at school (Barsade et al, 2003; Hareli and Rafaeli, 2008; Robinson, Watkins and Harmon-Jones, 2013). In the light of the foregoing, there is still a lack of research on how dispositional dimensions might influence early childhood teachers' working environment fit.

The main aim of the current study was to examine the predictive role of subjective happiness, work engagement, collective efficacy and some socio-contextual variables (self/coregulated proactive strategies) on teachers' working-environment fit in educational and scholastic services for 0/6 years old children. Drawing on Fredrickson's (2001) broaden-and-build theory of positive emotion, we argue that frequent positive affects triggered by subjective happiness at work should affect teacher work outcomes. According to the broaden-and-build theory, the presence of positive emotions at work broadens individuals' mindsets and builds individuals' resources, thereby enhancing their sensitivity, openness and consideration of their workplace (Fredrickson, 2013).

\section{Subjective happiness and work engagement}

Several individual aspects may have a role in influencing work experience. Among these, subjective happiness and dispositional positive affect towards others have been recently demonstrated to have a peculiar influence on people's adaptation at work (Boehm and Lyubomirsky, 2008).

The terms 'happiness' and 'subjective well-being' have been interchangeably used in positive psychology. Despite this, some authors claim for the use of 'subjective well-being' instead of 'happiness', as the first one is considered a more science-backed expression (see Diener et al., 2017 for a recent review of the terms). Interestingly, Lyubomirsky and Lepper (1999) underlined that happiness fits well into the subjectivist approach to well-being, as one of the criteria based on which people rate their well-being (Diener et al., 2017). Furthermore, they underlined that happiness may be considered as a dispositional measure of subjective well-being, that could be useful to explain why some people report higher subjective well-being depending on life changes, while others tend to report the same amount of subjective well-being regardless life events (Lyubomirsky and Lepper, 1999). Starting from these considerations, the authors proposed a construct, i.e. subjective happiness, in order to account for a dispositional measure of subjective well-being, that could explain the individual differences found within the subjectivist studies on well-being (Lyubomirsky and Lepper, 1999). The authors claimed that perceived global well-being differs depending on how individuals encode, interpret, and emotionally respond to life events. Accordingly, other studies have shown that dispositional measures of subjective well-being give a hint on how people adapt to situations, events and daily life (Lucas, 2007). This is consistent with the Broaden and Build Theory of positive emotions (Fredrickson, 2001), according to which, by experiencing frequent positive affects, people broaden cognitive and behavioural repertoire and build personal resources such as self-efficacy, resilience and optimism. Therefore, dispositional subjective well-being may have a role in predicting how people manage their work experiences, too (Lyubomirsky, King and Diener 2005). Consistently, studies have shown that high dispositional subjective well-being has several positive consequences at work, in terms of higher performance, higher success and higher social support 
from and to colleagues (Boehm and Lyubomirsky, 2008). Interestingly, happier workers have been shown to better engage in "organizational citizenship" behaviours, namely altruistic, conscientious and cooperative behaviours that improve the general climate and productivity at work (Boehm and Lyubomirsky, 2008). Moreover, happier workers better manage workload and occupational stress and make better decisions at work improving job performance (Warr, 2007).

Several studies carried out till now have confirmed the linkage between subjective happiness (as a personal resource) and engagement at the workplace (Bakker and Oerlemans, 2016) but, surprisingly, there is still a limited literature on this relationship among teachers.

Work engagement has been defined as "a state of fulfilment that is characterized by vigour, dedication, and absorption". Namely, vigour refers to the energy and the willingness to put extra efforts and be persistent in one's work; dedication is characterized by being strongly involved in one's work as well as experiencing a sense of meaningfulness, enthusiasm, and inspiration; absorption refers to being fully concentrated and happily engrossed in one's work, whereby time passes quickly (Schaufeli et al., 2002).

Work engagement has emerged as predictive of job performance, low intention to quit teaching as well as having a "contagious" effect on positive teacher-student relationships and on pupils' academic achievements (Salanova et al., 2010).

\section{Self/co-regulated proactive strategies and collective self-efficacy}

Teachers' cognitive and behavioural efforts to manage work-related stress that are referred as coping strategies can include self- or co-regulation strategies, or both (Parker et al., 2012). Self-regulation strategies refer to teacher's self-generated cognitive, emotional and behavioural strategies to cope with work stressors. The social resources constitute co-regulation strategies which in turn facilitate meaningful goal orientation and reduce burnout (Xanthopoulou et al., 2009). The use of direct actions rather than indirect and avoidant strategies make teachers'more effective in coping with the challenges and demands of their work; such positive actions, in turn, increase job satisfaction and work engagement (Salmela-Aro, Tolvanen and Nurmi, 2011). Soini, Pyhältö and Pietarinen (2010) found that teachers who experience a positive work tend to use problem-solving strategies and co-regulate their behaviour with their colleagues' one in social context. In line with this, prior research shows that a positive social climate is related to teacher satisfaction and motivation (Skaalvik and Skaalvik, 2011). Teachers who perceived high level of social support from colleagues have reported a lower intention to leave teaching than those with a low level of support (Pomaki et al., 2010). In the school context, perceived self-efficacy appears deeply linked to the group's functioning. Perceived collective self-efficacy represents teachers' beliefs on the colleagues' skills employed for planning actions to achieve specific objectives. There are only a few studies that have examined this variable, assuming that perceived collective self-efficacy represents a determining factor for the subjective work experience. A number of studies have proven the pivotal role played by proactive strategies, in reducing teaching stress and developing a better working environment (Pietarinen et al., 2013). The relevance of addressing such strategies lies in the fact that the learning and the use of them depend on the social interaction of the schools where the teachers work, therefore they can be intentionally promoted and sustained (Pietarinen et al., 2013). Proactive strategies adopted by teachers may not only reduce the risk of burnout but also contribute to develop a positive working environment and increasing work engagement. 


\section{Material and methods}

Participants and Procedure

Our sample was composed of 189 full-time in-service early childhood teachers ( $89 \%$ female) from Rome, Italy. Ages ranged from 27 to $63(\mathrm{M}=36.03$ years, $\mathrm{SD}=10.15)$. In terms of marital status, $56.5 \%$ were married, $21.6 \%$ were single, $18.4 \%$ were separated/ divorced, and $1 \%$ was widowed. Participants who took part spontaneously to the research after plenary presentation of the research project at school received written information on Italian privacy regulations, and signed informed consent. The research was conducted following the APA's ethical principles and Code of Conduct (American Psychological Association, 2002).

Measures

The Subjective Happiness Scale (Lyubomirsky and Lepper, 1999) is a 4-item scale aimed at assessing subjective happiness, using a 7-point Likert scale. The first two items ask people to rate how they are generally happy about their life $(1=$ not a very happy person, $7=$ a very happy person) and how happy they are in comparison with their peers $(1=$ less happy, $7=$ more happy); the last two items ask respondents on the extent the characterization of an happy and of an unhappy person describes themselves $(1=$ not at all, $7=$ a great deal $)$. Higher scores on this measure indicate greater subjective happiness. Prior studies have reported Cronbach's alpha coefficients for the SHS from .79 to .94 (Lyubomirsky and Lepper, 1999). In the current study Cronbach's alpha was .71.

The Utrecht Work Engagement Scale (UWES-17; Schaufeli and Bakker, 2004, Italian version of UWES-17, validated by Balducci, Fraccaroli and Schaufeli, 2010) assesses work engagement. The scale is composed of 17 items, grouped into three subscales. Namely: vigour (six items), dedication (five items), and absorption (six items). All items are scored on a 7-point frequency rating scale ranging from 0 (never) to 6 (always). Cronbach's alpha was .96.

The Proactive Strategy scale (Salmela-Aro,2009) consists of seven items, measuring two factors of proactive strategies: a) self-regulation (4 items) and b) co-regulation (3 items), meaning, respectively, the ability to identify and use resources for coping with stressors and the ability to seek and receive social support from colleagues. All items were rated on a 7-point Likert-type scale, ranging from 1 (completely disagree) to 7 (completely agree). Cronbach's alpha was .69.

The Teacher-working environment fit scale (Pyhältö, Pietarinen and Salmela-Aro, 2011) consists of 6 items, measuring two dimensions: a) received professional recognition (3 items) and b) constructive and enabling work climate ( 3 items). The professional recognition dimension measures the appreciation individual experienced by the teacher as a member of a professional community. The second dimension measures the teacher's shared capacity to contribute to the optimal fit within the professional community, as experienced by the respondent (i.e. the environment-centred approach to the perceived fit). All items were rated on a 7-point Likert scale ranging from 1 (completely disagree) to 7 (completely agree). Cronbach's alpha was .67.

\section{Results}

Bivariate Analyses

Bivariate correlations among the studied variables are all positive and are presented in Table 1. Subjective happiness was significantly correlated with work engagement $(r=.40, p<$ $.01)$, teachers' self- $(r=.46, p<.01)$ and co-regulation strategies $(r=.42, p<.01)$. Both 
teachers' self- regulation $(r=.37, p<.01)$ and co-regulation $(r=.47, p<.01)$ strategies were significantly correlated with working environment fit and also with work engagement (respectively $r=.48, p<.01 ; r=.51, p<.01$ ). Finally a significant correlation emerged between teachers' work engagement and working environment fit $(r=.37, p<.01)$ and between collective efficacy and working environment fit $(r=.38, p<.01)$.

Multivariate Analyses

A multiple regression analysis was conducted to further investigate the contributions of relevant correlated independent variables to variance of the working environment fit. Hierarchical multiple regression was performed to separately assess the contributions of each variable. In line with the literature reviewed in the Introduction, socio-demographic variables were block-entered at the first step, followed by subjective happiness and work engagement at the second step, and regulation strategies with collective self-efficacy at the third. The results of the regression analysis are presented in Table 2.

Table 1. Bivariate Correlations among studied variables

\begin{tabular}{|c|c|c|c|c|c|c|c|c|c|}
\hline & 1 & 2 & 3 & 4 & 5 & 6 & 7 & 8 & 9 \\
\hline 1.Age & 1 & $.20 * *$ & $.26 * *$ & .09 & .00 & .03 & -.06 & $.11 *$ & -.06 \\
\hline 2.Marital status & & 1 & $.16^{* *}$ & .01 & .04 & .04 & -.04 & .01 & -.07 \\
\hline 3.Seniority & & & 1 & $.18^{* *}$ & .10 & .09 & -.03 & .09 & -.08 \\
\hline 4.Work Engagement & & & & 1 & $.48 * *$ & $.51 * *$ & $.37 * *$ & $.40 * *$ & $.25 * *$ \\
\hline 5.Self-regulationstrategies & & & & & 1 & $.67 * *$ & $.37 * *$ & $.46^{* *}$ & $.29 * *$ \\
\hline 6.Co-regulationstrategies & & & & & & 1 & $.47 * *$ & $.42 * *$ & $.21 * *$ \\
\hline $\begin{array}{l}\text { 7.Working Environment } \\
\text { Fit }\end{array}$ & & & & & & & 1 & $.13^{*}$ & $.38 * *$ \\
\hline 8.Happiness & & & & & & & & 1 & $.12 *$ \\
\hline 9.Collective Self-Efficacy & & & & & & & & & 1 \\
\hline
\end{tabular}

Table 2. Regression Coefficients for Predictors of Working Environment Fit

\begin{tabular}{|c|c|c|c|c|c|c|c|c|c|c|c|}
\hline \multirow{3}{*}{ Variables } & \multicolumn{11}{|c|}{ Working Environment Fit } \\
\hline & \multicolumn{4}{|c|}{ Step1 } & \multicolumn{4}{|c|}{ Step2 } & \multicolumn{3}{|c|}{ Step3 } \\
\hline & $\mathbf{B}$ & E.S. & $\beta$ & p & B & E.S. & $\beta$ & p & B & E.S. & $\beta$ \\
\hline Age & -.019 & .023 & -.049 & .40 & -.029 & .021 & -.074 & .18 & -.017 & .019 & -.044 \\
\hline Marital status & -.229 & .491 & -.027 & .64 & -.126 & .455 & -.015 & .78 & -.158 & .408 & -.019 \\
\hline Seniority & -.006 & .027 & -.012 & .83 & -.038 & .025 & -.082 & .14 & -.026 & .023 & -.058 \\
\hline $\begin{array}{l}\text { Subjective } \\
\text { Happiness }\end{array}$ & & & & & -.007 & .087 & -.005 & .93 & -.175 & .083 & .115 \\
\hline $\begin{array}{l}\text { Work } \\
\text { Engagement }\end{array}$ & & & & & .175 & .026 & .390 & .00 & .074 & .026 & .166 \\
\hline $\begin{array}{l}\text { Self-regulation } \\
\text { strategies }\end{array}$ & & & & & & & & & .021 & .094 & .015 \\
\hline $\begin{array}{l}\text { Co-regulation } \\
\text { strategies }\end{array}$ & & & & & & & & & .696 & .122 & .379 \\
\hline $\begin{array}{l}\text { Collective } \\
\text { efficacy }\end{array}$ & & & & & & & & & .202 & .040 & .252 \\
\hline $\mathrm{R}$ & .06 & & & & .38 & & & & .57 & & \\
\hline $\mathrm{R}^{2}$ & .00 & & & & .15 & & & & .33 & & \\
\hline$\Delta \mathrm{R}^{2}$ & & & & & .15 & & & & .18 & & \\
\hline
\end{tabular}


Hierarchical multiple regression revealed that the model as a whole accounted for $33 \%$ of the variance in working environment fit $(\mathrm{F}(8,181)=18.859, p<.001)$. Teachers' proactive coregulation strategies $(\beta=.379, \mathrm{t}=5.713, \mathrm{p}<.001)$, perceived collective self-efficacy $(\beta=.252, \mathrm{t}$ $=5.015, \mathrm{p}<.001)$, work engagement levels $(\beta=.166, \mathrm{t}=2.857, \mathrm{p}=.005)$, and subjective happiness $(\beta=.115, \mathrm{t}=-2.105, \mathrm{p}=.036)$ all positive predicted working environment fit.

\section{Discussions}

Our study aimed to consider possible relations between work environment fit and some dispositional and socio-contextual variables, namely: subjective well-being, work engagement, collective efficacy and the use of self/co-regulated proactive strategies, in teachers involved in educational and scholastic services for children between 0 and 6 years old. Fit or misfit in scholastic environment shows a strong impact on teachers' well-being, affecting job commitment and performance.

As expected, the results confirmed what previous research evidenced: teachers' subjective well-being, work engagement, and use of self/co-regulated proactive strategies were positive correlated to work environment fit.

According to the findings of regression model analysis conducted, the work environment fit variance was positively predicted by the use of proactive co-regulated strategies, collective self-efficacy, work engagement levels and subjective happiness. The identification of factors sustaining teachers in their work environment represents a considerable resource, preventing the risk of distress and avoiding its extreme consequences, such as burnout and turnover.

In order to tolerate and manage stressful conditions, teachers may resort to several self- or co-regulated coping strategies (Parker et al., 2012). Self-regulated strategies are identified by teachers on their own, when facing particularly stressful conditions; by contrast, co-regulated strategies consist in the identification and use of social resources in managing work-related solicitations.

The performed analysis shows that the utilization of proactive co-regulated strategies can contribute to workers' perception of environmental fit in the context of educational services. The observed results confirm data from literature; using socially oriented strategies, teachers are able to realize a better regulation of their behaviour in relation to everyday working conditions, improving environment fit (Ciucci et al., 2018; Salmela-Aro, Tolvanen and Nurmi, 2011).

According to Pietarinen et al. (2013), the use of co-regulated strategies in a composite group of teachers was associated to lower levels of discomfort experienced in working and to the perception of fit felt in their work environment; furthermore, according to these authors, the planning of specific interventions may actively sustain operators' well-being. Moreover, Bakker, Tims and Derks (2012) report the relationship between the levels of well-being perceived at work and the use of proactive co-regulated strategies, expressed in the systematic research of colleagues' support and cooperation. The use of proactive co-regulated strategies is described as associated to new problem-solving strategies and to an unusual and flexible use of the available resources (Linnenbrink-Garcia et al., 2011), with effects on work-related well-being. The perception of a social climate founded on an effective support from the group of colleagues significantly affects teachers' satisfaction and motivation at work (Skaalvik and Skaalvik, 2011). The abovementioned variables may lower work-related stress, even when challenging working conditions are perceived as particularly intense (Pomaki et al., 2010). In addition to the reduced risk of burnout, the use of proactive social strategies may promote a positive work climate, improving cooperation among colleagues. Teachers who feel more supported by their coworkers are less oriented to quit their jobs, compared to those who experience lower levels of social support (Pomaki et al., 2010). Studies concerning educational context, describe teachers' 
attitude to use complex co-regulated strategies, as protective factors in reducing emotional depletion.

The school is a complex work environment. Our results show that social and relational dimensions play a considerable role within the scholastic and educational contexts; teachers interact not only with infants or students, but also with families and members of the professional community. Usually, the organization and planning of scholastic activities takes place in groups of teachers, rather than in a single professional; team's functioning seems to be an important premise for individual work outcomes and for personal self-efficacy (Skaalvik and Skaalvik, 2007). According to our results, environment fit can be predicted by the perception of collective efficacy, defined as the set of teachers' beliefs concerning colleagues' skills in planning effective actions, in order to reach specific goals. In the last decades, a limited number of studies took into account the aforementioned construct. The perception of collective efficacy can be crucial for individual self-efficacy in educational context; researches hypothesized that teachers' selfefficacy is strongly related to colleagues' perception of collective functioning, as well as to students' academic outcomes (Skaalvik and Skaalvik, 2007). Higher levels of collective efficacy, together with the perception of encouraging expectations from colleagues and principals, sustain teachers in the global management of their work, in particular improving their perception of work-related well-being (ibidem); by contrast, teachers may feel less motivated when an adequate support from colleagues' community is not perceived, with subsequent effects on their work with students.

From the performed regression model analysis, we observed that teachers and educators' environmental fit may be positively predicted by some dispositional variables, as work engagement and subjective happiness.

As confirmed by data in literature, the work engagement has a predictive role in job performance, teacher-students relationship and academic achievements. Furthermore, it has been associated to lower levels of perceived stress and lower intentions to quit work, enhancing job satisfaction and performance in working (Xanthopoulou et al., 2009).

According to existing literature, the perceived levels of subjective happiness may determine people capability to face and manage ordinary challenging situations (Lucas, 2007). According to Bakker et al. (2014), in scholastic contexts subjective well-being may encourage positive work experiences, sustaining teachers in a more productive use their own resources more productively, on both individual and relational levels (Bakker et al., 2014). Experimenting positive emotions in working, through high levels of subjective happiness and positive dispositional affects, may contribute to enlarge possible cognitions and actions', consolidating the available individual resources.

Subjective well-being may induce positive effects in terms of a better job performance, commitment and higher levels of perceived social support (Boehm and Lyubomirsky, 2008); furthermore, higher levels of subjective happiness have been associated to a better work organizational climate, determining significant positive effects in global productivity levels (Boehm and Lyubomirsky, 2008). Researchers describe that higher levels of personal well-being may sustain workers in facing stressors, more effectively managing work solicitations, through the activation of personal cognitive and behavioural resources (Warr, 2007). In line with the "Broaden-and-Build-Theory of positive emotions" (Fredrickson, 2001), subjective well-being can play a role in the way in which people face their experience in work environments, with consequent positive effects on working outcomes, performance and success (Lyubomirsky, King and Diener 2005). According to literature, happier workers show more altruistic and cooperative behaviours, actively contributing to a better working climate, with favourable productivity outcomes (Boehm and Lyubomirsky, 2008); furthermore, their work experience seem to be characterized by a more effective management of stressful conditions, with positive problemsolving strategies (Warr, 2007). 


\section{Conclusions}

This study can be addressed to the empirical perspective of Positive Psychology and examined the principal factors associated to work-related well-being in the educational and scholastic contexts. The performed analysis gives a significant insight on the aspects that can promote educators/teacher's environment fit in these peculiar and characteristic environments.

According to these results, proactive co-regulated strategies and collective efficacy showed to positively predict levels of environment fit, confirming the relational nature of the considered contexts; moreover, the role of dispositional variables, represented by subjective happiness, and work engagement, was confirm.

Specific interventions may be planned, in order to promote personal and environmental resources in educational contexts, enhancing operators' environment fit and, thus, their overall work-related well-being. Interventions may represent the possibility for workers to reflect on personal resources and tools, being occasions for sharing personal experiences and growth.

Future perspectives may also include the analysis of the relationship between the abovementioned variables in a longitudinal perspective, including an in-depth qualitative analysis of teachers' experiences, instead of the utilization of self-report tools.

\section{Bibliography}

1. Bakker, A.B., Tims, M. and Derks, D., 2012. Proactive personality and job performance: The role of job crafting and work engagement. Human relations, 65(10), pp. 1359-1378.

2. Bakker, A.B., Demerouti, E. and Sanz-Vergel, A.I., 2014. Burnout and work engagement: The JD-R approach. Annu. Rev. Organ. Psychol. Organ. Behav., 1(1), pp. 389-411.

3. Bakker, A.B. and Oerlemans, W.G., 2016. Momentary work happiness as a function of enduring burnout and work engagement. The Journal of psychology, 150(6), pp. 755-778.

4. Balducci, C., Fraccaroli, F. and Schaufeli, W.B., 2010. Psychometric properties of the Italian version of the Utrecht Work Engagement Scale (UWES-9). European Journal of Psychological Assessment.

5. Barsade, S., Brief, A.P., Spataro, S.E. and Greenberg, J., 2003. The affective revolution in organizational behavior: The emergence of a paradigm. In J. Greenberg (Ed.), Organizational behavior: A management challenge. pp. 3-50, Mahwah, NJ: Lawrence Erlbaum.

6. Bermejo-Toro, L., Prieto-Ursúa, M. and Hernández, V., 2016. Towards a model of teacher well-being: Personal and job resources involved in teacher burnout and engagement. Educational Psychology, 36(3), pp. 481-501.

7. Boehm, J.K. and Lyubomirsky, S., 2008. Does happiness promote career success?. Journal of career assessment, 16(1), pp. 101-116.

8. Ciucci, E., Baroncelli, A., Toselli, M. and Denham, S.A., 2018. Personal and Professional Emotional Characteristics of Early Childhood Teachers and Their Proneness to Communicate with Parents and Colleagues about Children's Emotions. In Child \& Youth Care Forum, 47(2), pp. 303-316.

9. Diener, E., Heintzelman, S.J., Kushlev, K., Tay, L., Wirtz, D., Lutes, L. D. and Oishi, S., 2017. Findings all psychologists should know from the new science on subjective wellbeing. Canadian Psychology/Psychologie canadienne, 58(2), pp. 87-104.

10. Fredrickson, B.L., 2001. The role of positive emotions in positive psychology: The broadenand-build theory of positive emotions. American psychologist, 56(3), pp. 218-226.

11. Fredrickson, B.L., 2013. Positive emotions broaden and build. In E. A. Plant \& P. G. Devine (Ed.), Advances in experimental social psychology, Vol. 47. San Diego, CA: Academic Press. 
12. Hareli, S. and Rafaeli, A., 2008. Emotioncycles: On the social influence of emotion in organizations. Research in organizational behavior, 28, 35-59.

13. Hoy, A.W. and Spero, R.B., 2005. Changes in teacher efficacy during the early years of teaching: A comparison of four measures. Teaching and teacher education, 21(4), pp. 343356.

14. Johnson, S.M., Kraft, M.A. and Papay, J.P., 2012. How context matters in high-need schools: The effects of teachers' working conditions on their professional satisfaction and their students' achievement. Teachers College Record, 114, pp. 1-39.

15. Leiter, M.P., Day, A., Oore, D.G. and Spence Laschinger, H.K., 2012. Getting better and staying better: Assessing civility, incivility, distress, and job attitudes one year after a civility intervention. Journal of occupational health psychology, 17(4), pp. 425.

16. Linnenbrink-Garcia, L., Rogat, T.K. and Koskey, K.L., 2011. Affect and engagement during small group instruction. Contemporary Educational Psychology, 36(1), pp. 13-24.

17. Lyubomirsky, S. and Lepper, H.S., 1999. A measure of subjective happiness: Preliminary reliability and construct validation. Social indicators research, 46(2), pp. 137-155.

18. Lyubomirsky, S., King, L. and Diener, E., 2005. The benefits of frequent positive affect: Does happiness lead to success?. Psychological bulletin, 131(6), pp. 803-855.

19. Lucas, R.E., 2007. Adaptation and the set-point model of subjective well-being: Does happiness change after major life events?. Current Directions in Psychological Science, 16(2), pp. 75-79.

20. Parker, P.D., Martin, A.J., Colmar, S. and Liem, G.A., 2012. Teachers' workplace wellbeing: Exploring a process model of goal orientation, coping behavior, engagement, and burnout. Teaching and Teacher Education, 28(4), pp. 503-513.

21. Pietarinen, J., Pyhältö, K., Soini, T. and Salmela-Aro, K., 2013. Reducing teacher burnout: A socio-contextual approach. Teaching and Teacher Education, 35, pp. 62-72.

22. Pomaki, G., DeLongis, A., Frey, D., Short, K. and Woehrle, T., 2010. When the going gets tough: Direct, buffering and indirect effects of social support on turnover intention. Teaching and Teacher Education, 26(6), pp. 1340-1346.

23. Pyhältö, K., Pietarinen, J. and Salmela-Aro, K., 2011. Teacher-working-environment fit as a framework for burnout experienced by Finnish teachers. Teaching and Teacher Education, 27(7), pp. 1101-1110.

24. Robinson, M.D., Watkins, E.R., and Harmon-Jones, E. (Eds.). 2013. Handbook of cognition and emotion. New York, NY: Guilford Press.

25. Salanova, M., Schaufeli, W. B., Xanthopoulou, D. and Bakker, A.B., 2010. In A.B. Bakker and M.P. Leiter (Ed.), Work engagement: A handbook of essential theory and research (pp. 118-131). New York, NY: Psychology Press.

26. Salmela-Aro, K. 2009. Personal goals and well-being during critical life transitions: the 4 C's e channeling, choice, co-agency and compensation. Advances in Life Course Research, 14, pp. 63-73.

27. Salmela-Aro, K., Tolvanen, A. and Nurmi, J. E., 2011. Social strategies during university studies predict early career work burnout and engagement: 18-year longitudinal study. Journal of Vocational Behavior, 79(1), pp. 145-157.

28. Schaufeli, W.B., Salanova, M., González-Romá, V. and Bakker, A.B., 2002. The measurement of engagement and burnout: A two sample confirmatory factor analytic approach. Journal of Happiness studies, 3(1), pp. 71-92.

29. Skaalvik, E.M. and Skaalvik, S., 2007. Dimensions of teacher self-efficacy and relations with strain factors, perceived collective teacher efficacy, and teacher burnout. Journal of educational psychology, 99(3), pp. 611. 
30. Skaalvik, E.M. and Skaalvik, S., 2011. Teacher job satisfaction and motivation to leave the teaching profession: Relations with school context, feeling of belonging, and emotional exhaustion. Teaching and teacher education, 27(6), pp. 1029-1038.

31. Soini, T., Pyhältö, K. and Pietarinen, J., 2010. Pedagogical well-being: reflecting learning and well-being in teachers' work. Teachers and Teaching: theory and practice, 16(6), pp. 735-751.

32. Stoeber, J. and Rennert, D., 2008. Perfectionism in school teachers: Relations with stress appraisals, coping styles, and burnout. Anxiety, stress, and coping, 21(1), pp. 37-53.

33. Warr, P. 2007. Work, happiness, and unhappiness, Mahwah, NJ: Lawrence Erlbaum Associates, Inc.

34. Xanthopoulou, D., Bakker, A.B., Demerouti, E. and Schaufeli, W.B., 2009. Reciprocal relationships between job resources, personal resources, and work engagement. Journal of Vocational behavior, 74(3), pp. 235-244.

35. ***American Psychological Association, 2002. Ethical principles of psychologists and code of conduct. American psychologist, 57(12), pp. 1060-1073. 